\title{
Nesiritide as an adjunctive therapy in adult patients with heart failure undergoing high-risk cardiac surgery
}

\author{
Louis E. Samuels, MD, ${ }^{a}$ Elena C. Holmes, CRNP, a and Lee Letwin, MD, ${ }^{b}$ Wynnewood, Pa
}

T

he use of nesiritide has been shown to be efficacious in patients with decompensated heart failure. ${ }^{1}$ The role of nesiritide in cardiac surgery, however, remains undetermined. The purpose of this report is to document our initial experience with nesiritide as an adjunctive therapy in adult patients with heart failure undergoing high-risk cardiac surgery.

\section{Patients and Methods}

Between October 2003 and January 2004, a total of 12 patients with advanced heart failure underwent cardiac surgery by a single surgeon (L.E.S.) at a single center. The use of nesiritide was determined by 4 intraoperative criteria: (1) congestive heart failure (New York Heart Association functional class III-IV), (2) pulmonary hypertension (systolic pulmonary arterial pressure [PAP] $>40 \mathrm{~mm} \mathrm{Hg}$ ), (3) low cardiac index (CI. $<2.0 \mathrm{~L} /\left[\mathrm{min} \cdot \mathrm{m}^{2}\right]$ ), and (4) elevated central venous pressure (CVP, $>15 \mathrm{~mm} \mathrm{Hg}$ ). Patients with and without renal insufficiency were included. Nesiritide was instituted as an infusion $(0.01 \mu \mathrm{g} /[\mathrm{kg} \cdot \min ])$ after placement of a Swan-Ganz catheter (Edwards Lifesciences, Irvine, Calif). The infusion was continued after the operation until the desired hemodynamic state was established. Other cardiac medications were administered as needed to augment cardiac output (eg, milrinone), systemic blood pressure (eg, norepinephrine), and arrhythmia control (eg, amiodarone). Hemodynamic parameters (systemic blood pressure, PAP, CVP, and CI) were measured immediately before, during, and 24 hours after surgery. In addition, the serum creatinine level was measured before surgery and on the first postoperative day. The urinary output was measured continuously and recorded 24 hours after admission to the intensive care unit.

\section{Results}

There were 8 women and 4 men with a mean age of 67.1 years (range 45-83 years). There were 4 coronary artery bypass grafting operations, 4 valvular operations, 3 combined coronary and valvular operations, and 1 ventricular assist device procedure (Table 1). Before nesiritide infusion, the mean systolic blood pressure was

\footnotetext{
From the Departments of Cardiothoracic Surgery ${ }^{\mathrm{a}}$ and Cardiothoracic Anesthesia, ${ }^{\mathrm{b}}$ Lankenau Hospital, Wynnewood, Pa.

Received for publication Feb 9, 2004; accepted for publication Feb 23, 2004.

Address for reprints: Louis E. Samuels, MD, Lankenau Hospital, 100 Lancaster Ave, MSB Suite \#280, Wynnewood, PA 19096 (E-mail: SamuelsLE@aol.com).

J Thorac Cardiovasc Surg 2004;128:627-9

$0022-5223 / \$ 30.00$

Copyright @ 2004 by The American Association for Thoracic Surgery

doi:10.1016/j.jtcvs.2004.02.025
}

$115 \mathrm{~mm} \mathrm{Hg}$, the mean systolic PAP was $63.5 \mathrm{~mm} \mathrm{Hg}$, the mean CVP was $22.5 \mathrm{~mm} \mathrm{Hg}$, and the mean CI was $1.7 \mathrm{~L} /\left(\mathrm{min} \cdot \mathrm{m}^{2}\right)$. The mean baseline serum creatinine level was $1.3 \mathrm{~g} / \mathrm{dL}$. After the operation, the mean systolic blood pressure was $114 \mathrm{~mm} \mathrm{Hg}$, the mean systolic PAP was $40.1 \mathrm{~mm} \mathrm{Hg}$, the mean CVP was $14 \mathrm{~mm}$ $\mathrm{Hg}$, and the mean $\mathrm{CI}$ was $2.5 \mathrm{~L} /\left(\mathrm{min} \cdot \mathrm{m}^{2}\right)$ (Table 2). The mean urinary output for the first 24 postoperative hours was $2290 \mathrm{~mL}$. The mean postoperative serum creatinine level was $1.4 \mathrm{~g} / \mathrm{dL}$. The mean ventilator time, intensive care unit stay, and postoperative length of stay were 9.5 hours, 2.3 days, and 8 days, respectively. There were no deaths and 6 morbidities: 1 surgical hemorrhage requiring re-exploration, 2 cases of prolonged mechanical ventilation ( $>24$ hours), and 3 new-onset atrial fibrillations. No patient required discontinuation of nesiritide before the establishment of an optimal hemodynamic state. Nesiritide infusion remained at $0.01 \mu \mathrm{g} /(\mathrm{kg} \cdot \min )$ during the entire infusion period. The mean duration of nesiritide therapy was 35 hours (range 24-48 hours).

\section{Discussion}

Nesiritide, human recombinant B-type natriuretic peptide, is among a family of natriuretic peptides with vasodilatory effects. Its role in the treatment of decompensated congestive heart failure is well established. Hemodynamic efficacy with direct and indirect cardiovascular and renal responses has been demonstrated. ${ }^{1} \mathrm{Ne}-$ siritide has been shown to directly augment coronary artery perfusion, ${ }^{2}$ reduce pulmonary capillary wedge pressure, PAP, and CVP, and indirectly improve cardiac output with no effect on heart rate. $^{3}$ Nesiritide has also been shown to increase urinary sodium excretion (natriuresis) and urinary volume while preserving creatinine clearance. ${ }^{4}$ Finally, nesiritide suppresses the release of norepinephrine, the release of endothelin 1 , and the renin-angiotensinaldosterone axis. ${ }^{5}$

The role of nesiritide in adult cardiac surgery is undefined. A limited number of studies have examined the use of nesiritide in various settings. ${ }^{6-8}$ Truong and associates, ${ }^{6}$ for example, described 24 patients requiring inotropic support (milrinone) who were evaluated for transplantation after a 24- to 48-hour nesiritide infusion. As a result of the improved hemodynamics, 14 patients were directly listed and 7 additional patients received elective-as opposed to emergency-left ventricular assist devices. Similarly, nesiritide therapy has been found to act favorably as an adjunct to the treatment of decompensated heart failure immediately after cardiac transplantation. ${ }^{7}$ Finally , Moazami and colleagues ${ }^{8}$ have described positive cardiovascular and renal effects in 2 patients given nesiritide after coronary artery bypass grafting. ${ }^{8}$

Our study adds to the experience of others in helping to define the role of nesiritide in cardiac surgery. As the complexity of cardiac surgery becomes more apparent, with sicker patients and weaker hearts, advanced pharmacologic therapies become neces- 
TABLE 1. Patient demographics

\begin{tabular}{|c|c|c|c|c|c|c|}
\hline Case & Procedure & Age (y) & Sex & Presentation & EF (\%) & NYHA class \\
\hline 1 & OРCAB & 72 & $\mathrm{~F}$ & Pulmonary edema & 20 & III \\
\hline 2 & AVR and $C A B G$ & 75 & $\mathrm{~F}$ & Pulmonary edema & 30 & III \\
\hline 3 & OPCAB & 83 & $F$ & Pulmonary edema & 25 & III \\
\hline 4 & AVR & 74 & M & Pulmonary edema & 20 & III \\
\hline 5 & ОРСAB & 63 & $\mathrm{~F}$ & Acute MI & 30 & III \\
\hline 6 & AVR and $C A B G$ & 58 & $\mathrm{~F}$ & Pulmonary edema & 10 & III \\
\hline 7 & MVR & 53 & M & Pulmonary edema & 25 & IV \\
\hline 8 & OPCAB & 68 & $\mathrm{~F}$ & Acute myocardial infarction & 20 & III \\
\hline 9 & LVAD & 45 & M & Ischemic cardiomyopathy & 10 & IV \\
\hline 10 & ОРСАВ & 77 & M & Pulmonary edema & 25 & III \\
\hline 11 & AVR and $C A B G$ & 76 & $\mathrm{~F}$ & Pulmonary edema & 30 & III \\
\hline 12 & AVR and MVR & 61 & $\mathrm{~F}$ & Pulmonary edema & 35 & IV \\
\hline
\end{tabular}

EF, Ejection fraction; NYHA, New York Heart Association; $O P C A B$, off-pump coronary artery bypass grafting; $A V R$, aortic valve replacement; $C A B G$, coronary artery bypass grafting; $M I$, myocardial infarction; $M V R$, mitral valve replacement; $L V A D$, left ventricular assist device.

TABLE 2. Hemodynamics

\begin{tabular}{|c|c|c|c|c|c|c|c|c|c|}
\hline \multirow[b]{2}{*}{ Case } & \multirow[b]{2}{*}{ Procedure } & \multicolumn{2}{|c|}{ SBP (mm Hg) } & \multicolumn{2}{|c|}{ sPAP (mm Hg) } & \multicolumn{2}{|c|}{ CVP (mm Hg) } & \multicolumn{2}{|c|}{$\mathrm{Cl}\left(\mathrm{L} /\left[\mathrm{min} / \mathrm{m}^{2}\right]\right)$} \\
\hline & & Preop & Postop & Preop & Postop & Preop & Postop & Preop & Postop \\
\hline 1 & OPCAB & 118 & 110 & 63 & 48 & 25 & 17 & 1.6 & 2.1 \\
\hline 2 & $A V R$ and $C A B G$ & 122 & 105 & 51 & 32 & 18 & 12 & 1.8 & 2.4 \\
\hline 3 & OРCAB & 97 & 112 & 54 & 41 & 21 & 13 & 1.4 & 2.2 \\
\hline 4 & AVR & 120 & 113 & 97 & 30 & 25 & 16 & 1.9 & 2.6 \\
\hline 5 & OPCAB & 130 & 120 & 48 & 42 & 19 & 6 & 1.6 & 2.6 \\
\hline 6 & AVR and $C A B G$ & 92 & 111 & 72 & 50 & 32 & 22 & 1.4 & 2.4 \\
\hline 7 & MVR & 126 & 104 & 84 & 50 & 30 & 14 & 1.7 & 2.6 \\
\hline 8 & OPCAB & 104 & 127 & 60 & 38 & 20 & 11 & 1.5 & 2.3 \\
\hline 9 & LVAD & 127 & 128 & 71 & 36 & 22 & 15 & 1.8 & 2.5 \\
\hline 10 & OPCAB & 118 & 100 & 65 & 44 & 20 & 14 & 1.9 & 2.4 \\
\hline 11 & $A V R$ and $C A B G$ & 120 & 136 & 54 & 33 & 20 & 11 & 1.7 & 3.2 \\
\hline 12 & AVR and MVR & 112 & 105 & 45 & 37 & 18 & 12 & 1.9 & 2.5 \\
\hline Average & & 116 & 114 & 64 & 40 & 23 & 14 & 1.7 & 2.5 \\
\hline
\end{tabular}

$S B P$, Systemic blood pressure; $S P A P$, systolic PAP; Preop, preoperative; Postop, postoperative; OPCAB, off-pump coronary artery bypass grafting; AVR, aortic valve replacement; $C A B G$, coronary artery bypass grafting; $M V R$, mitral valve replacement; $L V A D$, left ventricular assist device.

sary for management. The properties of nesiritide lend themselves to the heart failure population, whether medical or surgical. In an effort to define nesiritide's role and application, we sought to establish a protocol in which a nesiritide infusion was instituted in patients with heart failure undergoing cardiac surgery. Specific parameters were defined in the operating room, and a simple infusion scheme was established. The infusion was kept constant until the desired hemodynamic status was achieved, often in combination with other cardiac medications (eg, milrinone). We found little role for loop diuretic and low-dose ("renal dose") dopamine. The use of norepinephrine was not uncommon, a consequence of the combined vasodilatory characteristics of milrinone and nesiritide. The duration of norepinephrine use was less than 48 hours and the dosage range was low. We did not observe any ventricular arrhythmias.

\section{Conclusions}

In our opinion, nesiritide therapy serves as an important adjunct in the management of patients with heart failure undergoing cardiac surgery. When combined with other cardiac medications, such as milrinone, a therapeutic balance of cardiovascular and renal effects is safe and practical.

\section{References}

1. Publication Committee for the VMAC Investigators (Vasodilatation in the Management of Acute CHF). Intravenous nesiritide vs nitroglycerin for treatment of decompensated congestive heart failure: a randomized controlled trial. JAMA. 2002;287:1531-40.

2. Michaels AD, Klein A, Madden JA. Effects of intravenous nesiritide on human coronary vasomotor regulation and myocardial oxygen uptake. Circulation. 2003;107:2697-701.

3. Colucci WS, Elkayam U, Horton DP, Abraham WT, Bourge RC, Johnson $\mathrm{AD}$, et al. Intravenous nesiritide, a natriuretic peptide, in the treatment of decompensated congestive heart failure. Nesiritide Study Group. N Engl J Med. 2000;343:246-53.

4. Marcus LS, Hart D, Packer M, Yushak M, Medina N, Danziger RS, et al. Hemodynamic and renal excretory effects of human brain natriuretic peptide infusion in patients with congestive heart failure. A doubleblind, placebo-controlled, randomized crossover trial. Circulation. 1996;94:3184-9.

5. Aronson D, Burger AJ. Intravenous nesiritide (human B-type natriuretic 
peptide) reduces plasma endothelin-1 levels in patients with decompensated congestive heart failure. Am J Cardiol. 2002;90:435-8.

6. Truong KM, Bernabei AF, Czerska B. Nesiritide use in end stage heart failure. J Heart Lung Transplant. 2003;22:1S:113.

7. Tann SM. B-Natriuretic peptide improves hemodynamics and renal function in heart transplant patients immediately after surgery. $J$ Heart Lung Transplant. 2003;22:1S:S257.

8. Moazami N, Damiano RJ, Bailey MS, Hess RL, Lawton JS, Moon MR, et al. Nesiritide (BNP) in the management of postoperative cardiac patients. Ann Thorac Surg. 2003;75:1974-6.

\title{
Transit-time flow measurement cannot detect wrong anastomosis of an internal thoracic artery with the cardiac vein in coronary artery surgery
}

\author{
Yoshiyuki Takami, MD, and Hiroshi Masumoto, MD, Kasugai, Japan
}

I n coronary artery surgery transit-time flow measurement is useful to determine graft patency and to detect graft failure intraoperatively. Previous reports have demonstrated the accuracy and reproducibility of this noninvasive and simple procedure. ${ }^{1-5}$ In this report, however, we describe a case of wrong anastomosis of the left internal thoracic artery (LITA) with the cardiac vein, which could not be detected with transit flow measurement.

\section{Clinical Summary}

A 72-year-old man with effort angina was referred for coronary artery surgery. His coronary angiograms revealed occlusion of the distal right coronary artery and significant stenosis of the left main stem, the proximal left anterior descending artery, and the proximal left circumflex artery. He underwent triple coronary artery bypass grafting during cardiopulmonary bypass. The LITA was grafted to the left anterior descending artery, the left radial artery to the obtuse marginal branch of the left circumflex artery, and the saphenous vein to the atrioventricular branch of the right coronary artery. The result of transit-time flow measurement of the LITA graft is demonstrated in Figure 1. The mean flow (Qm) was 48 $\mathrm{mL} / \mathrm{min}$, the pulsatility index ([Maximal flow - Minimal flow]/ $Q m$ ) was 1.6, and the percentage of insufficiency (Volume of backward flow/Volume of forward flow) was $0 \%$. The postoperative angiogram revealed that the LITA had been anastomosed with the cardiac vein (Figure 1, $B$ ), although both aorta-coronary grafts (radial artery and saphenous vein) were patent.

\footnotetext{
From the Division of Cardiovascular Surgery, Kasugai Municipal Hospital, Kasugai, Japan.

Received for publication Jan 29, 2004; accepted for publication Feb 23, 2004.

Address for reprints: Yoshiyuki Takami, MD, Division of Cardiovascular Surgery, Kasugai Municipal Hospital, 1-1-1 Takagi-cho, Kasugai City 486-8510, Japan (E-mail: cvs@ hospital.kasugai.aichi.jp).

J Thorac Cardiovasc Surg 2004;128:629-31

$0022-5223 / \$ 30.00$

Copyright $\odot 2004$ by The American Association for Thoracic Surgery

doi:10.1016/j.jtcvs.2004.02.032
}

\section{Discussion}

In the transit-time method it is neither necessary to know the vessel diameter nor to perform any complex calibrating procedures. Therefore intraoperative transit-time flow measurement has become increasingly popular to check the anastomotic quality in coronary artery bypass grafting. ${ }^{5}$ As we have already demonstrated in the quantitative angiographic evaluation, ${ }^{2,3}$ intraoperative $\mathrm{Qm}$ is closely related to the degree of the stenosis at the most stenotic portion of the anastomosis. However, we cannot completely rely on the Qm value to determine the anastomotic quality of the graft. It is possible to have a patent anastomosis with a low Qm because the optimal Qm varies with the dynamic character, including blood pressure, heart rate, coronary resistance, and graft diameter. ${ }^{1,5} \mathrm{We}$ cannot necessarily judge a graft with a Qm of less than $20 \mathrm{~mL} / \mathrm{min}$ as nonpatent in the operating room. In contrast, surgeons can consider a graft with a Qm of greater than $20 \mathrm{~mL} / \mathrm{min}$ as patent. ${ }^{1}$ In addition, on the basis of the specific physiology of coronary circulation, patent graft flow is predominantly diastolic, forming a trapezoid-shaped waveform with a short systolic peak, as demonstrated in Figure 2. On the contrary, there is no diastolic flow in an occluded graft. ${ }^{2-4}$

In the patient in this report, the intraoperative Qm of the LITA was $48 \mathrm{~mL} / \mathrm{min}$, and its flow pattern was diastolic dominant. We considered the LITA as patent in the operating room. However, the postoperative angiogram revealed that the LITA had been accidentally anastomosed with the cardiac vein and not with the left coronary artery that we had intended to use for anastomosis. The arteriovenous flow pattern is similar to the arterioarterial flow pattern in coronary circulation. Although it is uncommon to perform incorrect grafting of the LITA to the cardiac vein, we should know that the transit-time flow measurement cannot differentiate the wrong anastomosis.

\section{References}

1. Jaber SF, Koenig SC, BhaskerRao B, et al. Role of graft flow measurement technique in anastomotic quality assessment in minimally invasive CABG. Ann Thorac Surg. 1998;66:1087-92.

2. Takami $\mathrm{Y}$, Ina $\mathrm{H}$. A simple method to determine anastomotic quality of coronary artery bypass grafting in the operating room. Cardiovasc Surg. 2001;9(5):499-503.

3. Takami Y, Ina H. Relation of intra-operative flow measurement with post-operative quantitative angiographic assessment of coronary artery bypass grafting. Ann Thorac Surg. 2001;72:1270-4. 